\title{
A Cancer Cell-Specific Inducer of Apoptosis
}

\author{
KATIE L. GREEN, ${ }^{1}$ CRAIG BROWN,${ }^{1}$ GERALDINE E. ROEDER,${ }^{1}$ THOMAS D. SOUTHGATE, ${ }^{2}$ \\ and KEVIN GASTON ${ }^{1}$
}

\begin{abstract}
Human papillomavirus (HPV) DNA is found in virtually all cervical cancers, strongly suggesting that these viruses are necessary to initiate this disease. The HPV E2 protein is required for viral replication, but E2 expression is usually lost in HPV-transformed cells because of the integration of viral DNA into the host chromosome. Several studies have shown that the reintroduction of E2 into HPV-transformed cells can induce growth arrest and apoptotic cell death. This raises the possibility that E2 could be useful in the treatment of HPV-induced disease. However, the effects of E2 on cell proliferation are not limited to HPV-transformed cells. The E2 protein from HPV type 16 can induce apoptosis via at least two pathways. One pathway involves the binding of E2 to p53 and operates in HPV-transformed cells, many non-HPV-transformed cell lines, and untransformed normal cells. The second pathway requires the binding of $\mathrm{E} 2$ to the viral genome and operates only in HPV-transformed cells. A mutation in E2 that significantly reduces the binding of this protein to p53 abrogates the induction of apoptosis in non-HPV-transformed cells and normal cells, but has no effect on the ability of the mutated protein to induce apoptosis in HPV-transformed cells. Here we show that a chimeric protein consisting of this mutant of E2, fused to the herpes simplex virus type 1 VP22 protein, can traffic between cells in a three-dimensional tumor model and induce apoptosis in HPV-transformed cells with high specificity. This cancer cell-specific inducer of apoptosis may be useful in the treatment of cervical cancer and other HPV-induced diseases.
\end{abstract}

\section{OVERVIEW SUMMARY}

Human papillomaviruses are generally agreed to be a necessary cause of cervical cancer and are thought to be important in several other types of malignant disease. Overexpression of the HPV-16 E2 protein induces apoptosis in HPV-transformed cells, suggesting that this protein might be useful in cancer therapy. However, this protein can also induce apoptosis in many non-HPV-transformed cell lines and in untransformed normal cells. We describe the production and use of a recombinant adenovirus that delivers a mutated E2 protein capable of inducing apoptosis in HPVtransformed cells but defective in the induction of apoptosis in non-HPV-transformed cell lines or untransformed cells.

\section{INTRODUCTION}

Oome TYPES of human papillomavirus (HPV) are accepted as
the cause of cervical cancer (Walboomers et al., 1999). HPV
DNA is present in virtually all cervical cancers and the viral
types found in these tumors encode oncoproteins that have been
shown to bring about cell transformation (reviewed by Dell and
Gaston, 2001). In much of the developed world, screening for
cervical cancer and its precursor lesions has significantly re-
duced mortality from this disease (Bray et al., 2005). However,
in Western Europe this disease is still the cause of about 10,000
deaths per year and in the developing world, cervical cancer re-
mains the second most prevalent cause of cancer-related death
in women (Yang et al., 2004; Parkin et al., 2005). HPV infec-
tion may also be an important factor in many other malignant

\footnotetext{
${ }^{1}$ Department of Biochemistry, School of Medical Sciences, University of Bristol, Bristol BS8 1TD, United Kingdom.

${ }^{2}$ Cancer Research UK Immunology Group, Paterson Institute for Cancer Research, Christie Hospital NHS Trust, Manchester M20 9BX, United Kingdom.
} 
diseases including cancer of the vulva, oral cancer, and skin cancer (Beckmann et al., 1988; Pfister, 1992; Schwartz et al., 1998; Basta et al., 1999). Because there are no treatments that specifically target cells containing HPV DNA, HPV-induced tumors are typically treated by surgery in combination with radiotherapy or nonspecific chemotherapy, or by surgery with both radiotherapy and chemotherapy (Kitchener, 2002; Dreyer, 2005). In the United Kingdom these nonspecific treatments have resulted in a 5-year age-standardized relative survival rate of about $60 \%$ for cervical cancer (Coleman et al., 2004). HPV vaccines should eventually reduce the impact of these viruses on human health (reviewed by Stern, 2005). However, HPV vaccines may not be useful for the treatment of existing disease. Furthermore, the vaccination of children against what is predominantly a sexually transmitted disease is likely to prove problematic in some populations. New and effective treatments for HPV-associated diseases are therefore still urgently required.

Apoptosis is a form of programmed cell death that allows cells that have been damaged, or otherwise compromised, to commit suicide. The $\mathrm{p} 53$ tumor suppressor protein plays an important role in some forms of apoptosis, mediating the effects of several apoptotic stimuli, such as DNA damage and cell stress (reviewed by Vousden, 2002). Many viral proteins impact on the cellular pathways that induce or suppress apoptosis. For instance, the E6 oncoproteins from HPV types associated with cancer, such as HPV-16 and HPV-18, bind to p53 and target this protein for degradation by the proteasome (Scheffner et al., 1990). These E6 oncoproteins lower the level of p53 within HPV-infected cells and this is thought to be important in the viral life cycle and in HPV-induced tumorigenesis (Munger et al., 1989a). The E7 oncoproteins from these HPV types can induce apoptosis in some cells (Jones et al., 1997; Webster et al., 2000). These E7 proteins interact with members of the retinoblastoma family of cellular tumor suppressor proteins (pRb, p107, and p130) and this is also thought to be important in the viral life cycle and HPV-induced tumorigenesis (Dyson et al., 1989; Munger et al., 1989b, 1991). Furthermore, we and others have shown that overexpression of the E2 proteins from these HPV types can induce apoptosis in some cells (Desaintes et al., 1997; Sanchez-Perez et al., 1997).

The HPV E2 proteins bind to specific sites within the HPV genome in order to regulate transcription of the viral genes and recruit the E1 helicase to the viral origin of replication (Storey et al., 1995; Thain et al., 1997). In HPV-infected cells, the HPV genome exists as an episomal DNA molecule that rarely, if ever, integrates into the host chromosome (Durst et al., 1985; Schwarz et al., 1985; Yee et al., 1985). In contrast, HPV-transformed cervical cancer cells often contain chromosomally integrated HPV DNA or, less frequently, a mixture of chromosomally integrated HPV DNA and episomal HPV DNA (Baker et al., 1987; Kalantari et al., 1998; Corden et al., 1999). These integration events often inactivate the E2 gene or otherwise prevent the expression of E2. This results in the deregulation of viral gene expression and suggests that the loss or inactivation of the E2 protein is important in tumorigenesis (Romanczuk and Howley, 1992; Hwang et al., 1993). In support of this hypothesis, disruption of the E2 gene in episomal HPV genomes results in increased cell transformation (Romanczuk and Howley, 1992). Overexpression of the E2 protein in HPV-trans- formed cervical cancer cells can reestablish the regulation of HPV gene expression, leading to growth arrest and/or apoptosis (Hwang et al., 1993, 1996; Goodwin et al., 1998; Desaintes et al., 1999; Francis et al., 2000; Nishimura et al., 2000). These observations gave rise to the proposal that E2 could be useful in the treatment of cervical cancer and other HPV-induced diseases. However, the HPV-16 E2 protein binds to $\mathrm{p} 53$ in vitro and in cells (Massimi et al., 1999) and can induce apoptosis in some HPV-negative cells (Hwang et al., 1993; Goodwin et al., 1998; Desaintes et al., 1999; Francis et al., 2000; Nishimura et al., 2000; Webster et al., 2000). This means that the E2 proteins can kill both normal and HPV-transformed cells and poses a serious obstacle to the use of this protein in the treatment of HPV-induced cancer. Our work has shown that a mutated E2 protein, which shows reduced binding to $\mathrm{p} 53$, fails to induce apoptosis in non-HPV-transformed cells but can still induce apoptosis in HPV-transformed cells (Parish et al., 2006). This mutated E2 protein has the potential to act as a cancer cell-specific inducer of apoptosis. These pathways are shown diagrammatically in Fig. 1.

The herpes simplex virus type 1 (HSV-1) VP22 protein is able to enter mammalian cells and this property has been exploited to deliver a variety of potentially therapeutic VP22 fusion proteins to target cells (Phelan et al., 1998; Elliott and O'Hare, 1999; Stroh et al., 2003). We have shown previously that VP22-E2 fusion proteins produced in mammalian cells or in bacteria can enter mammalian cells and induce apoptosis (Roeder et al., 2004). We have also shown that a recombinant adenovirus can be used to deliver VP22-E2 fusion proteins to target cells and that the VP22-E2 proteins produced in the adenovirus-infected cells are able to traffic into uninfected cells and induce apoptosis (Green et al., 2006). Here we show that the VP22-E2 fusion protein induces apoptosis in HPV-transformed cells, in some non-HPV-transformed cells, and in normal untransformed cells. In contrast, the VP22-E2 fusion protein in which E2 has been mutated at positions that reduce the
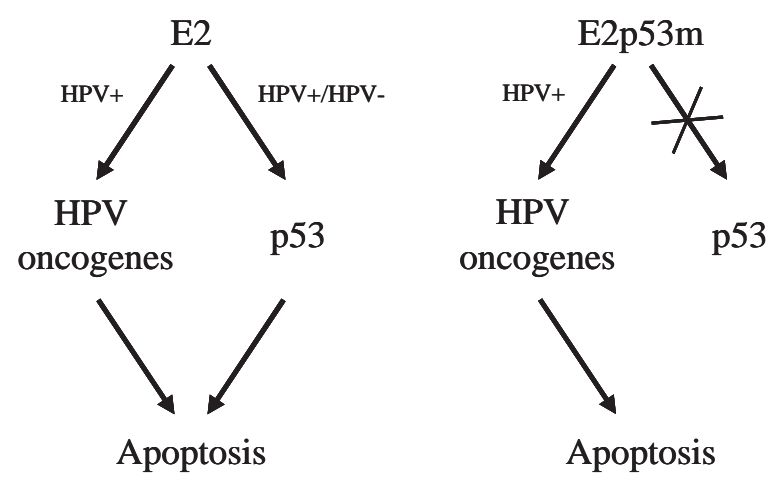

FIG. 1. Induction of apoptosis by E2 and E2p53m. A schematic representation of the pathways via which the HPV-16 E2 protein is known to induce apoptosis. HPV + and HPV-, pathways that are human papillomavirus (HPV) dependent and HPV independent, respectively. The E2p53m protein is defective in the induction of apoptosis via the HPV-independent pathway but is still able to induce apoptosis via the HPV-dependent pathway. 
binding of E2 to p53 specifically induces apoptosis in HPVtransformed cells.

\section{MATERIALS AND METHODS}

\section{Plasmids used in this study}

The plasmids pWEB-E2 and pWEB-E2p53m express the HPV-16 E2 protein and a mutated E2 protein with three amino acid substitutions: D338A, W341A, and D344A, respectively (Parish et al., 2006). To create a VP22-E2p53m fusion protein the E2p53m-coding sequence was cloned into plasmid pVP22 (Invitrogen, Carlsbad, CA) in frame with the VP22-coding sequence and immediately downstream of the human cytomegalovirus (CMV) promoter (exactly as described previously for the wild-type HPV-16 E2-coding sequence) (Roeder et al., 2004). To enable the purification of $\mathrm{E} 2 \mathrm{p} 53 \mathrm{~m}$ protein from bacterial cells a histidine tag was inserted upstream of the VP22coding sequence by cloning the oligonucleotide shown below into the unique HindIII site in this vector to produce pHisVP22-E2p53m:

\section{5'-AGCTTATTATGCATCATCACCATCACCATGGTGGTA-3'}

3'-ATAATACGTAGTAGTGGTAGTGGTACCACCATTCGA-5'

Recombinant adenoviral constructs expressing VP22 and VP22-E2 have been described previously (Green et al., 2006). To create an adenoviral construct expressing a VP22-E2p53m fusion protein, the CMV promoter and VP22-E2p53m-coding sequence were first excised from pVP22-E2p53m, using XbaI. The ends of this fragment were blunted and the fragment was digested with $X$ hoI before cloning into pAdlox vector that had previously been digested with EcoRI, blunt ended, and then digested with XhoI. The sequence and reading frame of all constructs were confirmed by DNA sequencing.

\section{Recombinant adenoviruses}

Recombinant adenoviruses were produced by calcium phosphate transfection of pAdlox plasmids into Cre8 HEK293 cells followed by infection with wild-type adenovirus $\Psi 5$. The viruses were plaque purified by end-point dilution on Cre8 HEK293 cells and extracted by 1,1,2-trichlorotrifluoroethane (Arklone P; INEOS Fluor, Runcorn, UK) purification exactly as described previously (Green et al., 2006). Viral preparations were double purified on cesium chloride gradients and stored at $-80^{\circ} \mathrm{C}$ until required. All preparations were assessed for lipopolysaccharide contamination, the presence of replicationcompetent adenovirus, and the ratio of infectious to defective particles before use. The recombinant adenoviral construct expressing GFP was a gift from R. Hawkins (Paterson Institute for Cancer Research, Manchester, UK) (Biglari et al., 2006).

\section{Proteins used in this study}

Histidine-tagged VP22, VP22-E2, and VP22-E2p53m were purified from overnight cultures of Escherichia coli BL21(DE3) cells containing pHisVP22, pHisVP22-E2, or pHisVP22E2p53m exactly as described previously for the HisVP22-E2 protein (Roeder et al., 2004). The purified proteins were analyzed by sodium dodecyl sulfate-polyacrylamide gel electrophoresis (SDS-PAGE) and used immediately or snap frozen in $30 \%$ glycerol and stored at $-80^{\circ} \mathrm{C}$ until required.

\section{Cell lines and conditioned media}

All cells were maintained in Dulbecco's modified Eagle's medium (DMEM) with $10 \%$ fetal bovine serum (FBS), penicillin ( $10^{5}$ units/liter), and streptomycin (100 mg/liter) with the following supplements: MCF-7 cells and HEK293 cells: glutamine ( $2 \mathrm{mmol} / \mathrm{liter}) ; 866$ cells, 879 cells, 808 cells, and 778 cells: insulin $(5 \mu \mathrm{g} / \mathrm{ml})$ with hydrocortisone $(0.01 \mu \mathrm{g} / \mathrm{ml}) ; 808 \mathrm{~F}$ cells and $873 \mathrm{~F}$ cells: insulin $(5 \mu \mathrm{g} / \mathrm{ml})$ with epidermal growth factor $(0.01 \mu \mathrm{g} / \mathrm{ml})$, cholera toxin $(0.01 \mu \mathrm{g} / \mathrm{ml})$, and hydrocortisone $(0.4 \mu \mathrm{g} / \mathrm{ml}) ; 873$ cells: insulin $(5 \mu \mathrm{g} / \mathrm{ml})$ with hydrocortisone $(0.01 \mu \mathrm{g} / \mathrm{ml})$ and $3 \mathrm{~T} 3$ feeder support; W12 cells: epidermal growth factor $(0.01 \mu \mathrm{g} / \mathrm{ml})$, cholera toxin $(0.01 \mu \mathrm{g} / \mathrm{ml})$, hydrocortisone $(0.4 \mu \mathrm{g} / \mathrm{ml})$, and 3T3 feeder support. The cells were maintained in a humidified atmosphere at $37^{\circ} \mathrm{C}$ and $5 \%$ $\mathrm{CO}_{2}$. Conditioned medium was produced by infecting Cos-7 cells with recombinant adenoviruses at a multiplicity of infection (MOI) of 30 . After $48 \mathrm{hr}$ at $37^{\circ} \mathrm{C}$ and $5 \% \mathrm{CO}_{2}$, the conditioned medium was filtered (pore size, $0.2 \mu \mathrm{m}$ ) to remove infected cells and other debris. Plaque assays on HEK293 cells were used to confirm the absence of viral particles in the conditioned medium before use.

\section{Transient transfections}

Cells were transiently transfected with Tfx-20 (Promega, Madison, WI) for Saos- 2 cells, 879 cells, CaSki cells, and 873F cells; with TfX-50 (Promega) for NIH3T3 cells and SiHa cells; and with FuGENE 6 (Roche Applied Science, Indianapolis, IN) for all other cells.

\section{Organotypic cell culture}

Organotypic cultures of SiHa cells were grown as described by Hubert and coworkers (1999) with minor modifications (Green et al., 2006). The cells were allowed to stratify for 2 weeks before adenoviral infection or the addition of purified VP22 or VP22-E2 protein. The rafts were embedded in paraffin $48 \mathrm{hr}$ posttreatment and then sectioned for immunohistochemistry.

\section{Immunohistochemistry}

Sections from raft cultures were stained for protein expression, using avidin, biotin, and peroxidase (VECTASTAIN ABC kit; Vector Laboratories, Burlingame, CA) with VP22 (Invitrogen) and GFP (Covance Research Products, Berkeley, CA) antibodies exactly as described previously (Green et al., 2006). Apoptosis was assessed using with M30 CytoDEATH antibodies (Roche Applied Science). In each section DNA was counterstained with propidium iodide or 4',6-diamidino-2phenylindole (DAPI) (Kowalczyk et al., 2005).

\section{Fluorescence microscopy and TUNEL assays}

Twenty-four hours before infection cells were seeded at $4 \times$ $10^{5}$ cells per well onto coverslips in 6-well plates and incubated 
at $37^{\circ} \mathrm{C}$ overnight in $5 \% \mathrm{CO}_{2}$. The cells were then infected with recombinant adenoviruses at an $\mathrm{MOI}$ of 30 . After $24 \mathrm{hr}$ at $37^{\circ} \mathrm{C}$ in $5 \% \mathrm{CO}_{2}$ the cells were fixed and stained as described previously (Green et al., 2006). Fluorescence microscopy was carried out with a Leica DMR epifluorescence microscope (Leica Microsystems, Wetzlar, Germany) with fluorescein isothiocyanate (FITC) and DAPI filter sets and a $\times 40$ air lens. VP22 and VP22-E2 fusion proteins were visualized with a VP22-specific monoclonal antibody (Invitrogen) with an FITC-conjugated anti-mouse secondary antibody (Sigma, St. Louis, MO). Terminal deoxynucleotidyltransferase (TdT)-mediated dUTPbiotin nick end-labeling (TUNEL) assays were performed with a DeadEnd fluorometric kit (Promega) with coverslips mounted with VECTASHIELD plus DAPI as described previously (Kowalczyk et al., 2005).

\section{Flow cytometry}

HeLa cells $\left(1 \times 10^{6}\right)$ were seeded in $25-\mathrm{cm}^{2}$ flasks $24 \mathrm{hr}$ before infection and incubated at $37^{\circ} \mathrm{C}$ in $5 \% \mathrm{CO}_{2}$. The cells were then infected at an MOI of 30 and incubated as described previously for a further $24 \mathrm{hr}$. Floating cells were harvested from the medium and pooled with adherent cells harvested after trypsinization. The pooled cells were then examined by flow cytometry (BD FACScan; BD Biosciences, San Jose, CA) exactly as described previously (Roeder et al., 2004).

\section{Western blotting}

Cos-7 cells $\left(1 \times 10^{6}\right)$ were infected with recombinant adenoviruses at an MOI of 30 . After $24 \mathrm{hr}$ at $37^{\circ} \mathrm{C}$ in $5 \% \mathrm{CO}_{2}$ the cells were harvested by trypsinization and lysed in $50 \mu \mathrm{l}$ of $150 \mathrm{~m} M \mathrm{NaCl}, 50 \mathrm{~m} M$ Tris (pH 7.5), 1.0\% SDS containing protease inhibitors (complete protease inhibitor cocktail; Roche Applied Science). The lysates were incubated with DNase and RNase as described previously (Green et al., 2006) and the proteins were separated on $10 \%$ SDS-polyacrylamide gels. After transfer to a polyvinylidene difluoride (PVDF) membrane, VP22 and VP22 fusion proteins were detected with a VP22-specific monoclonal antibody (Invitrogen) with an horseradish peroxidase (HRP)-conjugated antimouse secondary antibody (Santa Cruz Biotechnology, Santa Cruz, CA), and BM chemiluminescence blotting substrate (Roche Applied Science).

\section{RESULTS}

\section{E2p53m-induced apoptosis is restricted to HPV-transformed cells}

We have shown previously that the HPV-16 E2 protein can induce apoptosis in a variety of both HPV-transformed and nonHPV-transformed cell lines (Webster et al., 2000). We mutated the HPV-16 E2 protein at positions predicted to be critical for binding to 553 on the basis of molecular modeling and then examined the ability of the mutated protein to bind p53 and induce apoptosis (Parish et al., 2006). Trp341, Asp344, and Asp338 in E2 were simultaneously mutated to alanine and the resultant E2p53m protein was shown to bind p53 less tightly than the wild-type E2 protein. The E2 and E2p53m proteins were then expressed in a variety of cell types and TUNEL assays were used to determine the effect of each protein on the number of cells undergoing apoptosis (Parish et al., 2006). We have now extended this analysis to include a total of nine HPVtransformed cell lines, four non-HPV-transformed cell lines, and two primary cell types. Table 1 shows the pooled data. In all nine of the HPV-transformed cell lines tested, both E2 and E2p52m induced significant levels of apoptosis. In contrast, in the HPV-negative cell lines Saos-2, MCF-7, and NIH3T3, the wild-type E2 protein induced apoptosis whereas the E2p53m protein failed to induce apoptosis. Importantly, wild-type E2 induced apoptosis in $808 \mathrm{~F}$ and $873 \mathrm{~F}$ cells, two examples of normal nontransformed cervical fibroblast cells, whereas E2p53m failed to induce apoptosis in these cells.

All the non-HPV-transformed cells that underwent E2-induced apoptosis expressed wild-type p53 or, in the case of Saos2 cells, were p53-null but were cotransfected with a plasmid that expresses wild-type p53. Neither E2 nor E2p53m induced apoptosis in Saos-2 cells in the absence of coexpressed p53 (Table 1). Similarly, neither protein induced apoptosis in Cos7 cells, an HPV-negative cell line that expresses the simian virus 40 (SV40) T antigen. The SV40 T antigen sequesters p53 and inhibits p53 function (Mietz et al., 1992). Thus the data shown in Table 1 suggest that the Trp341, Asp344, and Asp338 mutations in E2 block the ability of E2 to induce apoptosis in nonHPV-transformed cell lines and normal cells that express functional wild-type p53. However, these mutations in E2 appear to have little or no effect on the ability of this protein to induce apoptosis in HPV-transformed cells.

Table 1. Induction of Apoptosis by E2 and E2p53m

\begin{tabular}{lcrrr}
\hline & & \multicolumn{3}{c}{ Apoptosis $(\%)^{\mathrm{a}}$} \\
\cline { 3 - 5 } Cell line & HPV status & Background & \multicolumn{1}{c}{ E2 } & E2p53m \\
\hline HeLa & HPV-18 & $3 \pm 2$ & $20 \pm 3$ & $28 \pm 5$ \\
SiHa & HPV-16 & $5 \pm 3$ & $32 \pm 4$ & $37 \pm 5$ \\
808 & HPV-18 & $9 \pm 2$ & $31 \pm 3$ & $29 \pm 3$ \\
866 & HPV-16 & $9 \pm 3$ & $28 \pm 4$ & $35 \pm 4$ \\
879 & HPV-16 & $9 \pm 4$ & $35 \pm 3$ & $38 \pm 4$ \\
ME180 & HPV-18 & $4 \pm 2$ & $20 \pm 4$ & $24 \pm 4$ \\
CaSki & HPV-16 & $11 \pm 3$ & $31 \pm 6$ & $36 \pm 3$ \\
778 & HPV-18 & $7 \pm 2$ & $19 \pm 2$ & $20 \pm 2$ \\
W12 & HPV-16 & $5 \pm 1$ & $16 \pm 2$ & $22 \pm 2$ \\
$808 \mathrm{~F}$ & Negative & $7 \pm 2$ & $19 \pm 2$ & $10 \pm 1$ \\
$873 F$ & Negative & $3 \pm 1$ & $13 \pm 2$ & $3 \pm 1$ \\
NIH3T3 & Negative & $2 \pm 1$ & $16 \pm 2$ & $5 \pm 1$ \\
MCF-7 & Negative & $6 \pm 1$ & $23 \pm 3$ & $10 \pm 1$ \\
Saos-2 & Negative & $10 \pm 1$ & $8 \pm 3$ & $10 \pm 3$ \\
Saos-2 + p53 & Negative & $10 \pm 1$ & $28 \pm 6$ & $8 \pm 1$ \\
Cos-7 & Negative & $5 \pm 3$ & $5 \pm 3$ & $6 \pm 3$ \\
\hline
\end{tabular}

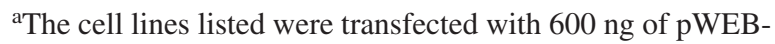
E2, pWEB-E2p53m, or the empty pWEB vector (background) and a GFP expression vector. Thirty hours posttransfection, the percentage of apoptotic cells in the transfected population was determined as described previously. Soas-2 cells are p53-null and were additionally cotransfected with $200 \mathrm{ng}$ of the p53 expression vector pCB6-p53. Some of these data are taken from our previously published work (Parish et al., 2006). 


\section{Recombinant adenovirus expressing VP22-E2p53m}

We have shown previously that unlike wild-type E2, VP22-E2 fusion proteins can traffic between cells (Roeder $e t$ al., 2004; Green et al., 2006). We constructed recombinant adenoviruses expressing VP22 and VP22-E2 and we showed that unlike VP22, the VP22-E2 fusion protein induces apoptosis in HPV-transformed cells. The ability to traffic between cells and to induce apoptosis makes VP22-E2 fusion proteins interesting as potential therapeutic agents. To compare the ability of VP22-E2 and VP22-E2p53m to traffic between cells and to induce apoptosis, we produced Ad VP22-E2p53m, a recombi- nant adenovirus expressing a VP22-E2p53m fusion protein (Fig. 2a). To confirm that the viruses express the relevant proteins, we infected Cos-7 cells at an MOI of 30. Cos-7 cells were used for this experiment because neither E2 protein induces apoptosis in these cells (see Table 1). After $24 \mathrm{hr}$ the infected cells were harvested, lysed, and assayed for the presence of VP22 and VP22-E2 fusion proteins by Western blotting, using a VP22 antibody. Bands corresponding to the predicted sizes of VP22-E2, and VP22-E2p53m were clearly present in lysates produced from cells infected with the corresponding viruses but were not present in a lysate produced from mock-infected cells (Fig. 2b). Immunofluorescence confirmed that VP22-E2 and a
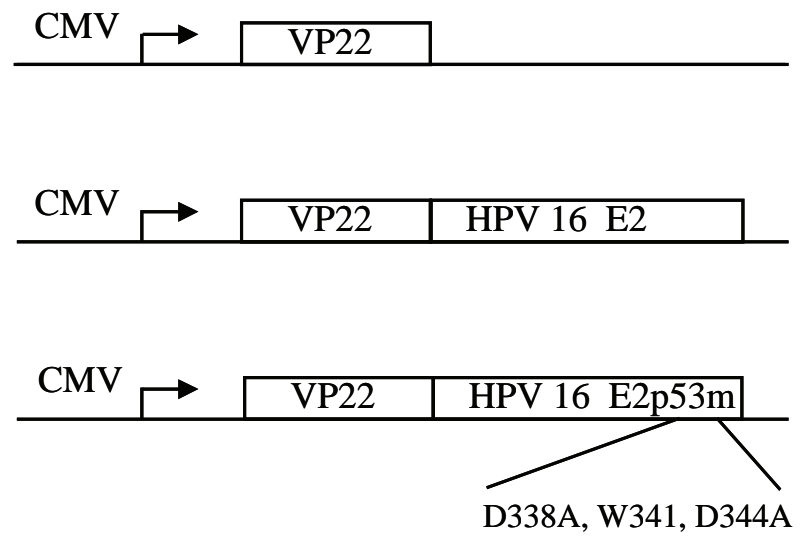

b

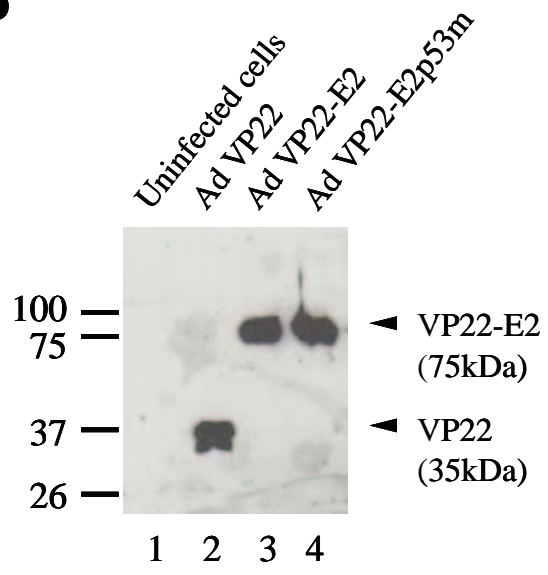
Ad VP22-E2p53m

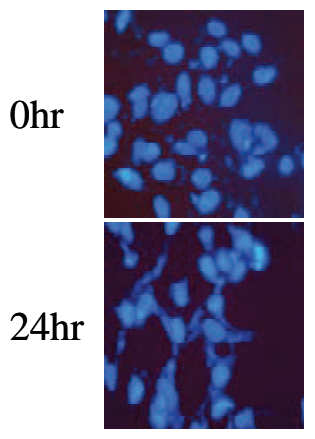

Ad VP22-E2
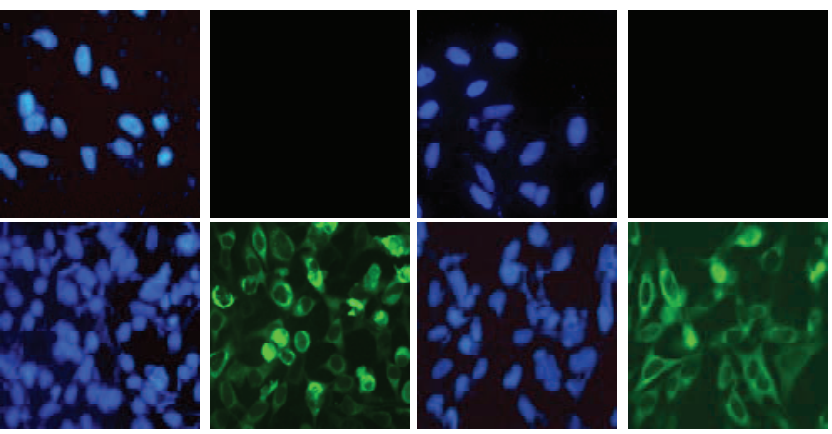

FIG. 2. Adenoviral vectors expressing VP22, VP22-E2, and VP22-E2p53m. (a) A schematic representation of the recombinant adenoviral constructs used in this study. The bottom line shows the mutations present in the E2p53m protein. (b) Cos-7 cells were infected with Ad VP22, Ad VP22-E2, and Ad VP22-E2p53m at an MOI of 30. Twenty-four hours postinfection, the cells were lysed and $50 \mu \mathrm{g}$ of total protein was loaded onto an SDS-10\% polyacrylamide gel for Western blotting. After electrophoresis the proteins were transferred to a polyvinylidene difluoride (PDVF) membrane and an anti-VP22 monoclonal antibody was used to detect VP22 and VP22 fusion proteins. The sizes of the marker proteins used are as indicated. (c) Immunofluorescence showing VP22, VP22-E2, and VP22-E2p53 expression in Cos-7 cells. Before infection, Cos-7 cells were seeded onto coverslips and allowed to adhere overnight. The cells were then infected with the viruses shown at an MOI of 30 . The cells were fixed 24 hr postinfection and stained with bisbenzimide. Immunofluorescence was performed with an anti-VP22 monoclonal antibody and an FITC-labeled secondary antibody. The cells were viewed with a Leica DMR epifluorescence microscope fitted with DAPI and FITC filter sets. 
VP22-E2p53m were expressed in most of the cells $24 \mathrm{hr}$ postinfection (Fig. 2c and quantified in Fig. 3a).

\section{Adenoviral VP22-E2p53m induces high levels of apoptosis in HeLa cells}

To compare the effects of Ad VP22-E2 and Ad VP22E2p53m on HPV-transformed cells, we first infected HeLa cells with the relevant adenoviral constructs at an MOI of 30 and at various time points postinfection we used immunofluorescence to determined the number of cells expressing VP22 fusion proteins. Both VP22-E2 and VP22-E2p5m were detectable in HeLa cells $12 \mathrm{hr}$ postinfection and both proteins were expressed in the majority of cells $48 \mathrm{hr}$ postinfection (Fig. 3a). We then used flow cytometry to compare the effects of these viruses on cell proliferation. HeLa cells infected with Ad VP22 showed a normal cell cycle distribution (Fig. 3b, top). In contrast, infection with Ad VP22-E2 or Ad VP22-E2p53m resulted in an increase in the proportion of sub- $\mathrm{G}_{0}$ cells and a decrease in the proportion of cells in $\mathrm{G}_{1}$ and $\mathrm{G}_{2} / \mathrm{M}$ (Fig. $3 \mathrm{~b}$, middle and bottom, respectively). These data are indicative of an increase in the number of apoptotic cells and this was confirmed in TUNEL assays. Infection with Ad VP22-E2 or Ad VP22-E2p53m resulted in a significant increase in the number of TUNEL-positive, apoptotic cells (Fig. 3c). Infection with Ad VP22 resulted in a much smaller increase in the number of apoptotic cells. It is important to note that TUNEL assays typically underestimate the number of apoptotic cells because cells in the late stages of apoptosis detach from the coverslips used in these experiments. Although most of the cells expressed E2 proteins $48 \mathrm{hr}$ postinfection at this MOI, only $20-30 \%$ of the cells were apoptotic at this time point. However, at later time points more cells entered apoptosis and by $72 \mathrm{hr}$ all the cells infected with Ad VP22-E2 and Ad VP22-E2p53m were dead (data not shown). In summary, the data shown in Fig. 3 confirm that $\mathrm{Ad}$ VP22-E2p53m, like Ad VP22-E2, induces apoptosis in these HPV-transformed cells and suggest that there is little if any difference in the efficiency with which these viruses kill HeLa cells.

\section{VP22-E2p53m-induced cell death is cell type specific}

We next set out to compare the effects of VP22-E2 and VP22-E2p53m on HPV-transformed and non-HPV-transformed cells in more detail. For these experiments we made use of three HPV-transformed cell lines (HeLa cells, SiHa cells, and ME180 cells), as well as MCF-7 cells, a non-HPV-transformed cell line that expresses wild-type $\mathrm{p} 53$, and two primary cell types. To determine whether these cells are equally permissive to adenoviral infection, we seeded cells onto coverslips and added each virus at an MOI of 30. At various time points postinfection the cells were then fixed and immunofluorescence was performed with the VP22 antibody. The number of VP22positive and VP22-negative cells was counted to determine the infection efficiency (Fig. 4a-e). The HPV-transformed cell lines expressed VP22 and the VP22 fusion proteins in about $80 \%$ of the cells $48 \mathrm{hr}$ postinfection (Fig. 4a and b, and Fig. 3a). Similarly, VP22 and the VP22 fusion proteins were expressed in about $60 \%$ of the MCF-7 cells $48 \mathrm{hr}$ postinfection (Fig. 4c). Norman human epithelial keratinocytes (NHEK cells) were also permissive to infection (Fig. 4d). However, only about 5-10\% of primary vascular smooth muscle (VSM) cells expressed VP22 or the VP22 fusion proteins $48 \mathrm{hr}$ postinfection (Fig. 4e).

The effect of each virus on the survival of these cell types was then determined by counting the number of viable cells. Each cell type was infected at an MOI of 30 and at various time points the number of viable cells was determined by counting (Fig. 5). As expected, given the results shown in Fig. 3, infection with Ad VP22-E2 or Ad VP22-E2p53m dramatically reduced the number of viable HeLa cells (Fig. 5a). In marked contrast, infection with Ad VP22 arrested the growth of these cells but did not reduce the number of viable cells. Similar results were seen with HPV-16-transformed SiHa cells and HPV18-transformed ME180 cells (Fig. 5b and c, respectively). In contrast, all three viruses arrested the growth of non-HPV transformed MCF-7 cells but did not significantly reduce the number of viable cells (Fig. 5d). Ad VP22 induced growth arrest in primary NHEK cells whereas Ad VP22-E2 and Ad VP22-E2 brought about a modest reduction in the number of viable cells (Fig. 5e). Somewhat surprisingly, Ad VP22-E2 and Ad VP22-E2p53m arrested the growth of VSM cells (Fig. 5f), despite the fact that these proteins are detected only in about $10 \%$ of the cells $48 \mathrm{hr}$ postinfection (see Fig. 4e). This could be because the proliferating cells in the population are more susceptible to viral infection.

To determine whether the reductions in the number of viable cells are a result of increased apoptosis, we performed TUNEL assays. For these experiments we used conditioned medium produced from adenovirus-infected Cos-7 cells. Cos-7 cells were infected with Ad VP22, Ad VP22-E2, or Ad VP22-E2p53m at an MOI of 30 for $24 \mathrm{hr}$, at which point conditioned medium was collected. The conditioned medium was filtered to remove any virally infected cells and other debris and then added to the panel of cell types described previously. Plaque assays were used to confirm that the filtered conditioned medium did not contain virus particles (data not shown). At various time points after the addition of conditioned medium the number of apoptotic cells was determined in TUNEL assays (Fig. 6). The conditioned media from Cos-7 cells infected with Ad VP22-E2 or Ad VP22-E2p53m induced high levels of apoptosis in HeLa cells (Fig. 6a). In contrast, conditioned medium from Cos-7 cells infected with Ad VP22, or medium from mock-infected cells, brought about a much smaller increase in the number of apoptotic cells. Essentially the same results were seen with the other HPV-transformed cells (Fig. 6b and c, respectively), although the increase in apoptosis seen in ME180 cells was more modest than that in HeLa cells and SiHa cells. In MCF-7 cells, NHEK cells, and VSM cells, conditioned medium from Cos-7 cells infected with Ad VP22-E2 brought about a significant increase in the level of apoptosis (Fig. 6d-f), whereas conditioned medium from Cos-7 cells infected with Ad VP22-E2p53m brought about a modest increase in the number of apoptotic cells, more in keeping with the modest increases seen when these cells were treated with conditioned medium from cells infected with Ad VP22 or from mock-infected cells. These data suggest that both VP22-E2 and VP22-E2p53m reduce the number of viable HPV-transformed cells by increasing the levels of apoptosis in the treated populations. In contrast, whereas VP22-E2 also induced significant increases in the levels of apoptosis in non-HPV-transformed cell types, VP22-E2p53m had much less effect in these cells. These data also indicate that 
a

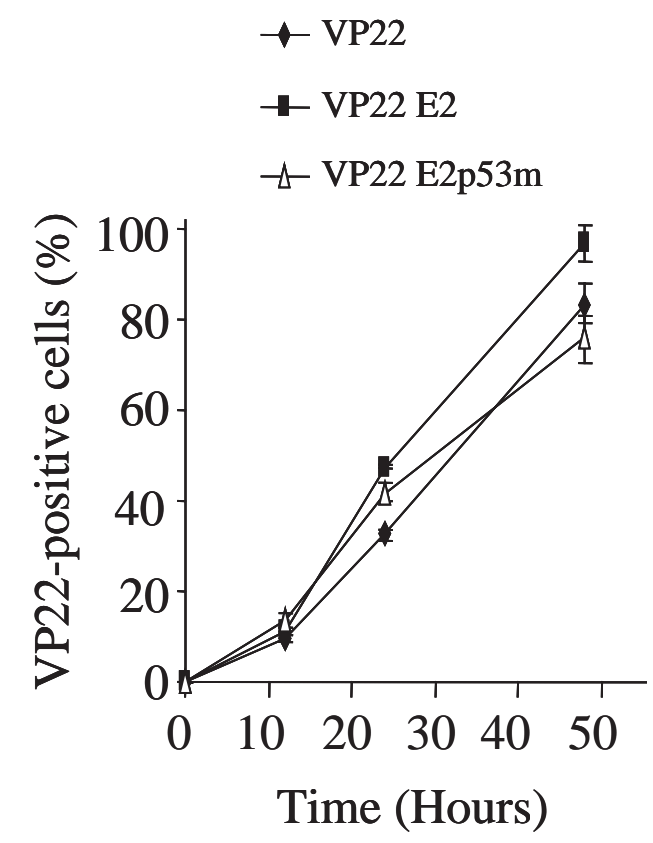

c

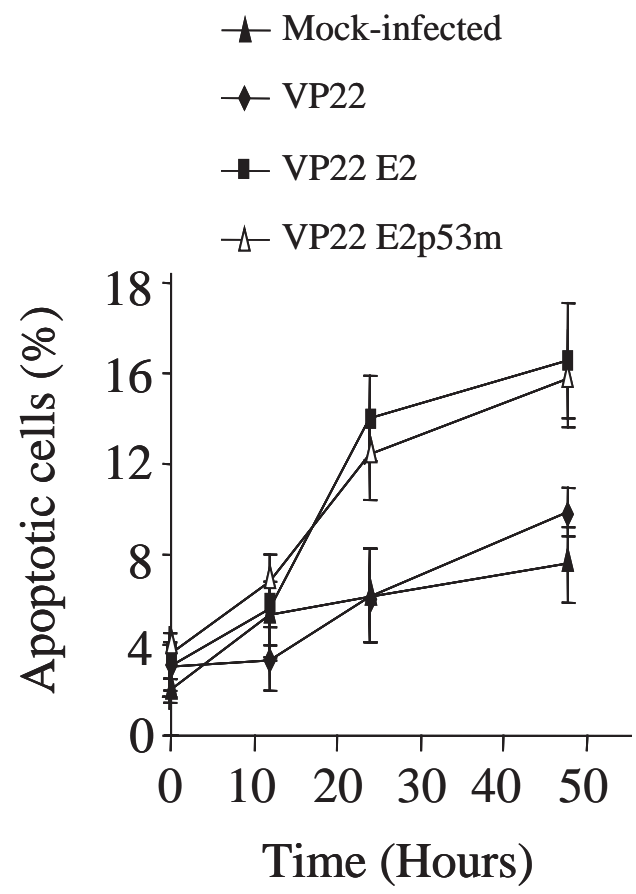

b
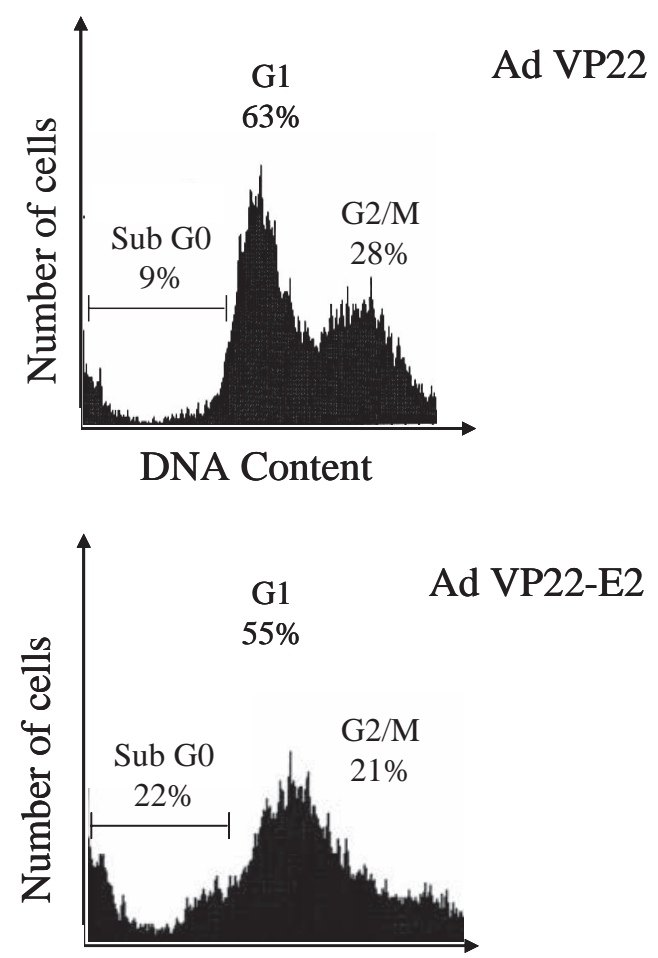

DNA Content

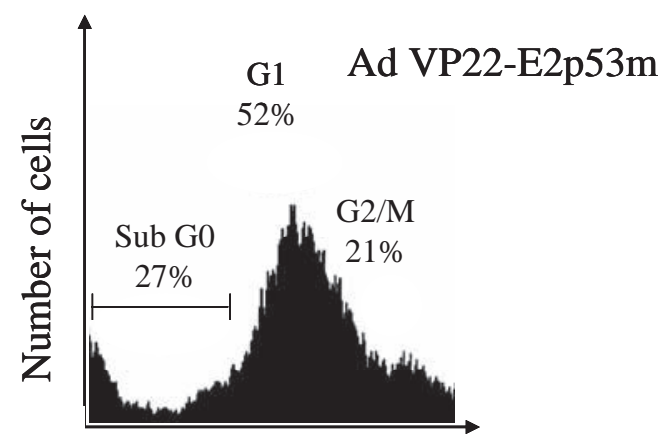

DNA Content

FIG. 3. Ad VP22-E2 and Ad VP22-E2p53m induce apoptosis in HeLa cells. (a) HeLa cells were infected with Ad VP22, Ad VP22-E2 or Ad VP22-E2p53m at an MOI of 30. At various time points after infection the cells were fixed and stained with bisbenzimide and VP22 proteins detected as described in Fig. 2c. The graph shows the number of cells expressing VP22 and the VP22-fusion proteins. The data are the mean and standard deviation of three independent experiments. (b) HeLa cells were infected with Ad VP22, Ad VP22-E2, or Ad VP22-E2p53m at an MOI of 30. Forty-eight hours postinfection, adherent and floating cells were collected and examined with a FACScan flow cytometer. The number of sub- $\mathrm{G}_{0}, \mathrm{G}_{1}$, and $\mathrm{G}_{2} / \mathrm{M}$ cells is indicated in each panel. Data are representative of those obtained in four independent experiments. (c) HeLa cells growing on coverslips were infected at an MOI of 30 with Ad VP22, Ad VP22-E2, or Ad VP22-E2p53m, or mock infected. At the times indicated the number of apoptotic cells was determined by TUNEL (terminal deoxynucleotidyltransferase [TdT]-mediated dUTP-biotin nick end-labeling) assay. Data represent the mean and standard deviation of three independent experiments. 
a

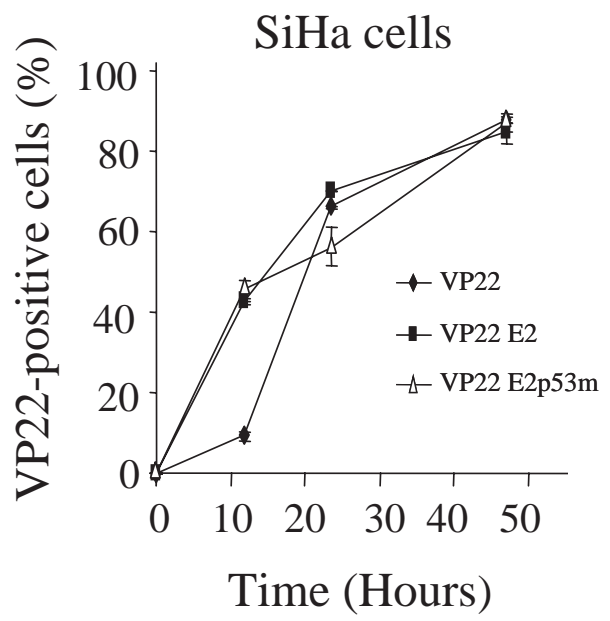

$\mathrm{c}$

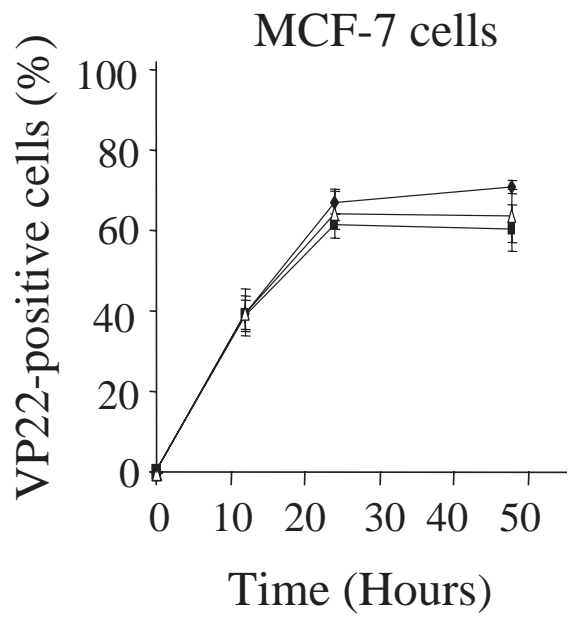

e

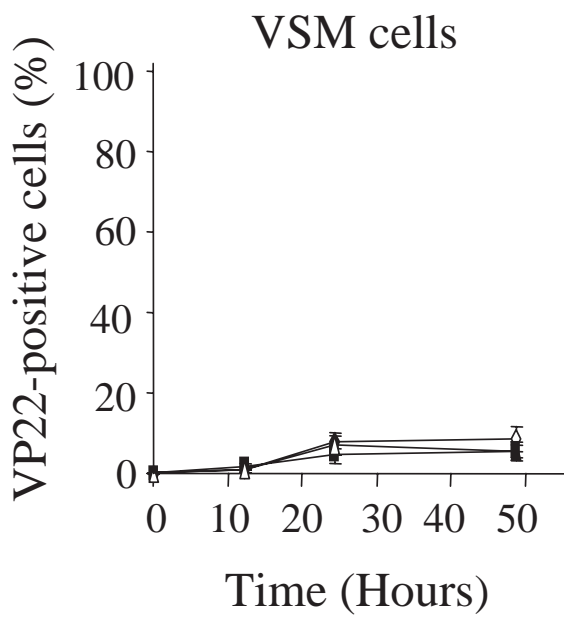

b

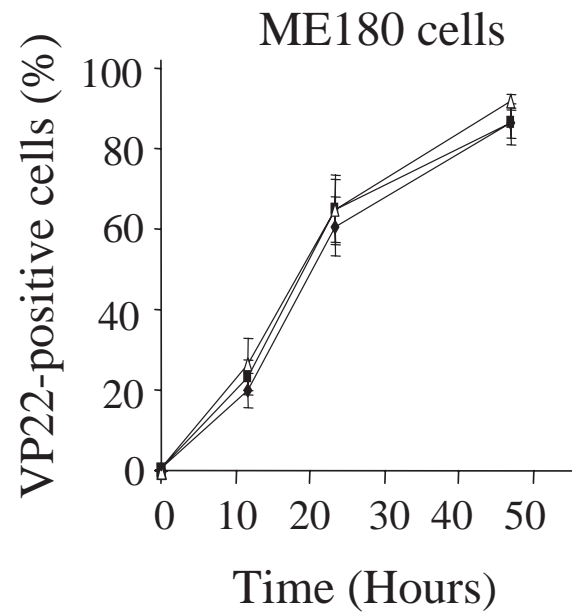

d

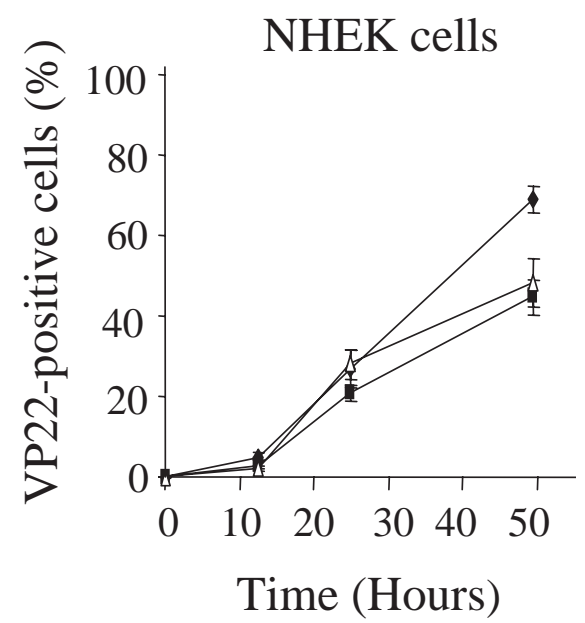

FIG. 4. Expression of VP22 and VP22 fusion proteins in various cell types. SiHa cells (a), ME180 cells (b), MCF-7 cells (c), NHEK cells (d), and VSM cells (e) were grown on coverslips before infection with Ad VP22, Ad VP22-E2, or Ad VP22-E2p53m at an MOI of 30. At the times indicated the cells were fixed and VP22 proteins were detected as described in Fig. 2c. The graphs show the number of cells expressing VP22 and the VP22 fusion proteins and the data represent the mean and standard deviation of three independent experiments. 
a

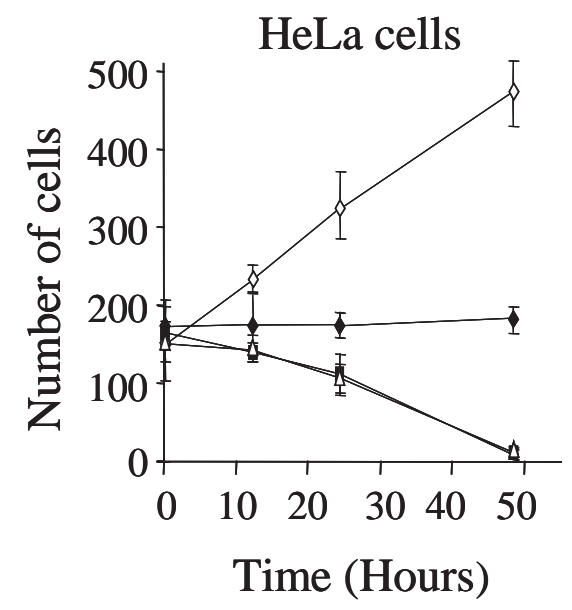

C

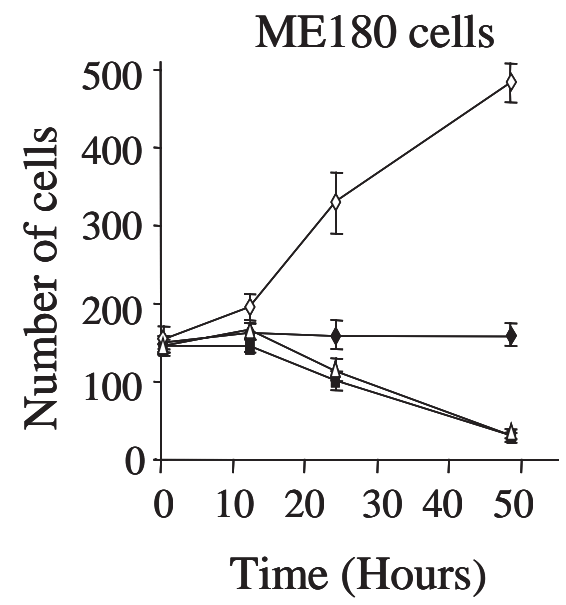

e

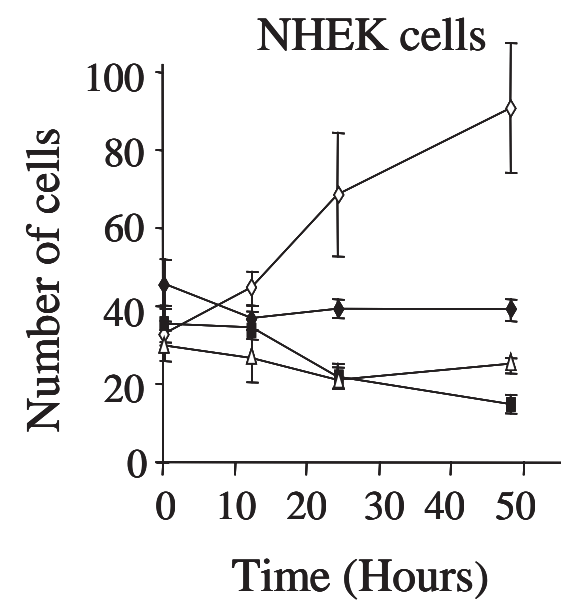

$\mathrm{b}$

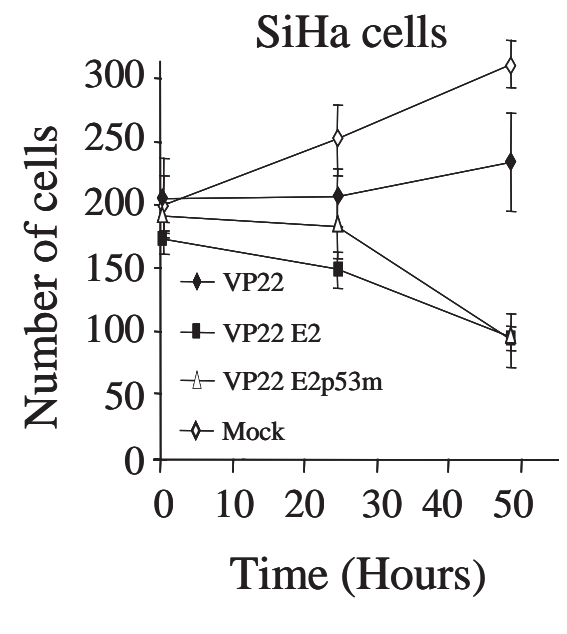

d

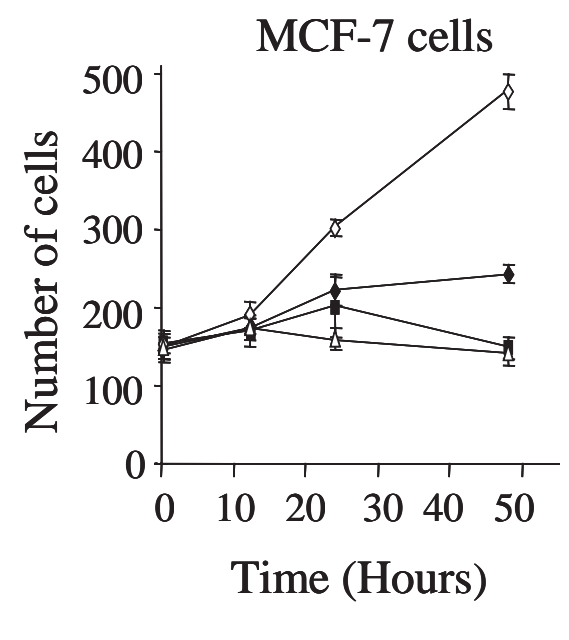

f

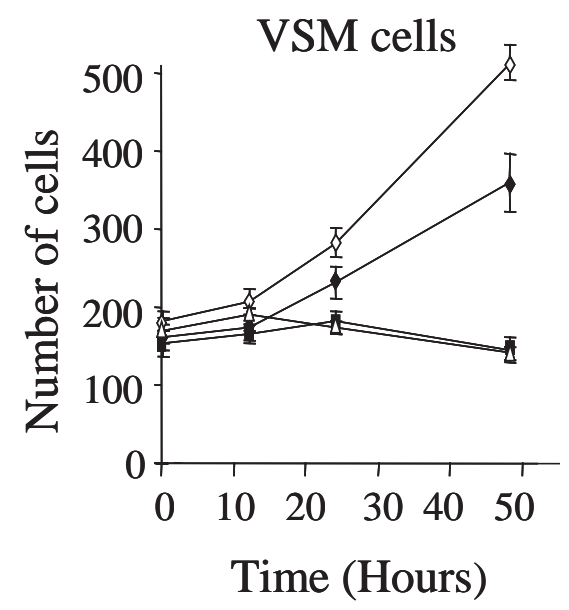

FIG. 5. Effects of VP22, Ad VP22-E2, and Ad VP22-E2p53m on cell proliferation. HeLa cells (a), SiHa cells (b), ME180 cells (c), MCF-7 cells (d), NHEK cells (e), and VSM cells (f) were grown on coverslips before infection with Ad VP22, Ad VP22-E2, or Ad VP22-E2p53m at an MOI of 30. At the times indicated the cells were fixed and stained with bisbenzimide. The number of cells per field of view was then counted with the aid of a Leica DMR epifluorescence microscope fitted with a DAPI filter set. The graphs show the number of surviving cells and the data represent the mean and standard deviation of three independent experiments. In (b) the data for Ad VP22 and Ad VP22-E2 were published previously without the Ad VP22-E2p53m data (Green et al., 2006). 
a

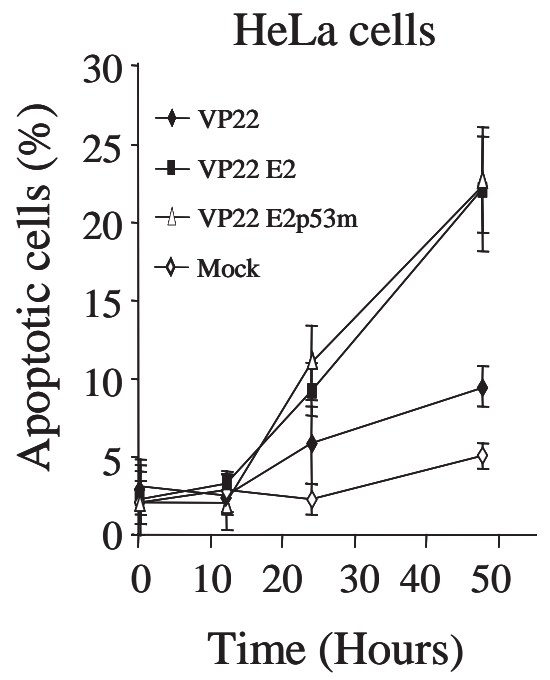

C

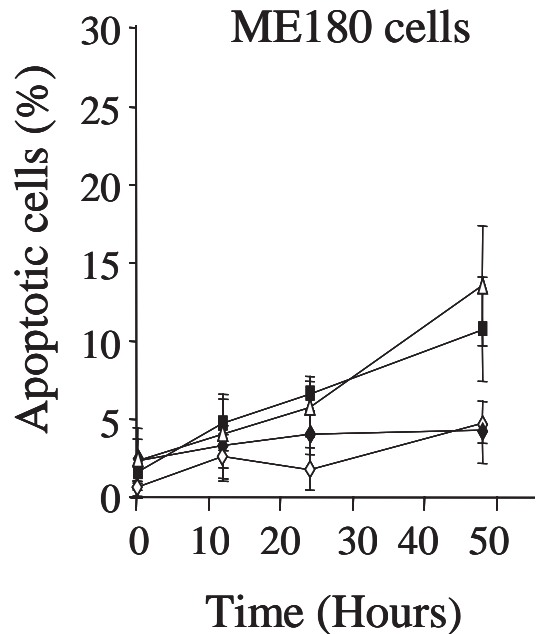

e

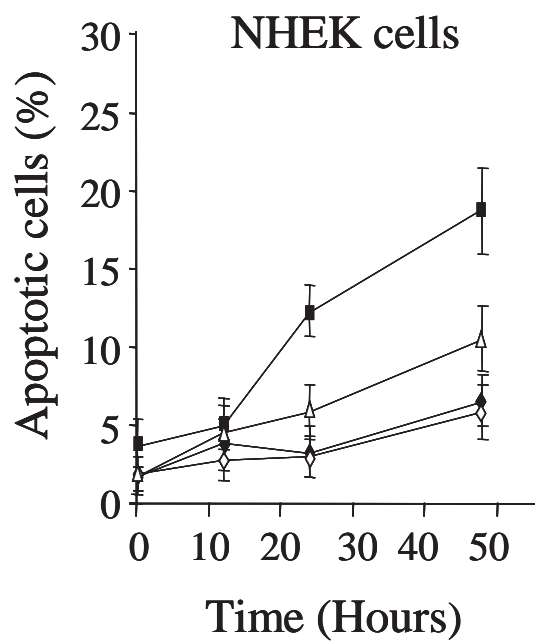

b

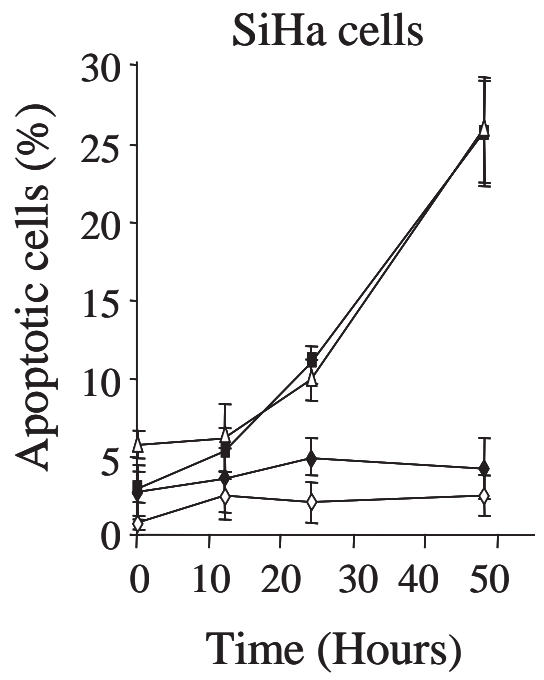

d

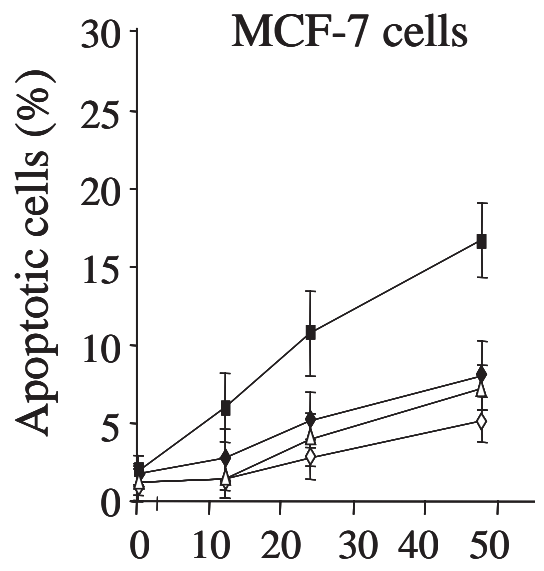

f

Time (Hours)

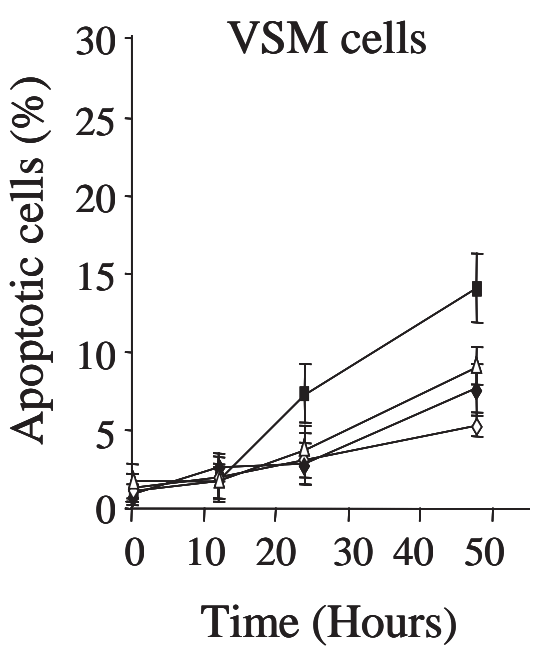

FIG. 6. Induction of apoptosis by VP22 and VP22-E2 fusion proteins. HeLa cells (a), SiHa cells (b), ME180 cells (c), MCF7 cells (d), NHEK cells (e), and VSM cells (f) were grown on coverslips before the addition of conditioned medium containing VP22, VP22-E2, or VP22-E2p53m. At the times indicated the cells were fixed and TUNEL assays were performed as described in Fig. 3c. Data represent the mean and standard deviation of three independent experiments. 
both proteins are able to exit the cells in which they are synthesized and induce apoptosis in nonproducing cells. This could explain why VP22-E2 is able to induce apoptosis in VSM cells despite the fact that these cells are poorly infected by Ad VP22-E2 (compare Fig. 4e and Fig. 6f). To confirm this conclusion we exposed VSM cells to conditioned medium and at various time points posttreatment we fixed the cells and performed immunofluorescence with the VP22 antibody. By $48 \mathrm{hr}$ posttreatment, about $40 \%$ of the conditioned medium-treated cells expressed VP22 or VP22 fusion proteins (data not shown). In contrast, by $48 \mathrm{hr}$ after adenoviral infection, only about $10 \%$ of the treated VSM cells expressed these proteins.

\section{VP22-E2p53m trafficks between cells and induces apoptosis in a three-dimensional tumor model}

VP22-E2 and VP22-E2p53m fusion proteins are both able to induce apoptosis in cells growing in monolayer cultures and this suggests that these proteins could be useful in cancer therapy. To compare the ability of these proteins to traffic between cells and to induce apoptosis in a more realistic setting, we turned to a three-dimensional tumor model. We have shown that both of these proteins can induce apoptosis in $\mathrm{SiHa}$ cells and inhibit the proliferation of these HPV-16-transformed cells (Figs. 6b and 5b, respectively). SiHa cells grown under organotypic culture conditions produce a three-dimensional raft of cells that closely resembles a cervical tumor (Hubert et al., 1999; Delvenne et al., 2001). To compare the trafficking of VP22-E2 and VP22-E2p53m in this three-dimensional tissue we applied adenoviruses to the top surface of SiHa rafts. After $48 \mathrm{hr}$ we embedded the rafts in paraffin and produced sections for immunohistochemical staining. To ensure that the staining patterns represented protein trafficking and not viral spreading, we mixed Ad VP22-E2 and Ad VP22-E2p53m with an adenovirus expressing green fluorescent protein (Ad GFP) before coinfection of the rafts and we stained adjacent sections for GFP and VP22. Whereas GFP staining was restricted to the top layers of the raft (Fig. 7a), VP22-E2 was present throughout almost the entire thickness of the rafts (Fig. 7b). The same result was obtained with Ad VP22-E2p53m and Ad VP22 (data not shown).

To identify apoptotic cells, adjacent sections were also subjected to immunohistochemical staining for a marker of apoptosis. The M30 antibody recognizes a target that is present only in cells undergoing apoptosis (Kusama et al., 2000). Staining with this antibody shows that rafts infected with Ad VP22-E2 or Ad VP22-E2p53m contained many apoptotic cells whereas rafts infected with Ad VP22 contained only a few apoptotic cells (Fig. 7c-e). These data indicate that like VP22-E2, the VP22-E2p53m protein can traffic from adenovirus-infected cells into uninfected cells and thereby penetrate the three-dimensional tumor model. Comparison with a DAPI-stained adjacent section (Fig. 7f) shows that the VP22-E2p53m protein induced apoptosis in the uninfected cells deep within the raft, almost as far as the basal layer.

\section{VP22-E2p53m produced in bacterial cells penetrates cell rafts and induces apoptosis}

Given the ability of VP22-E2p53m to traffic between cells and preferentially induce apoptosis in HPV-transformed cells it a

\section{$\alpha \mathrm{GFP}$}

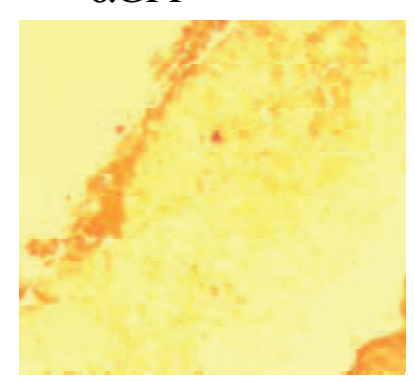

b

\section{$\alpha \mathrm{VP} 22-\mathrm{E} 2$}

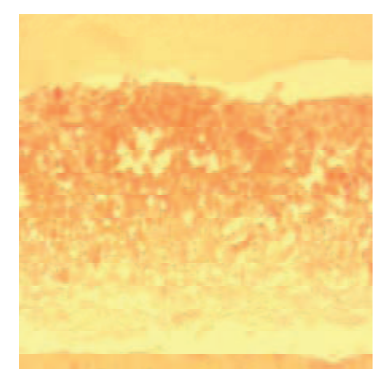

C

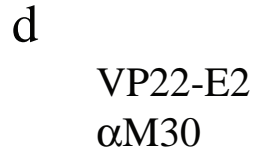

$\alpha \mathrm{M} 30$

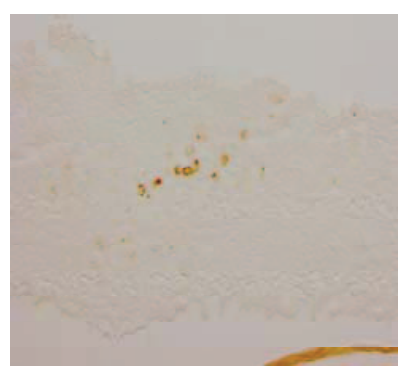

e

VP22-E2p53m $\alpha \mathrm{M} 30$
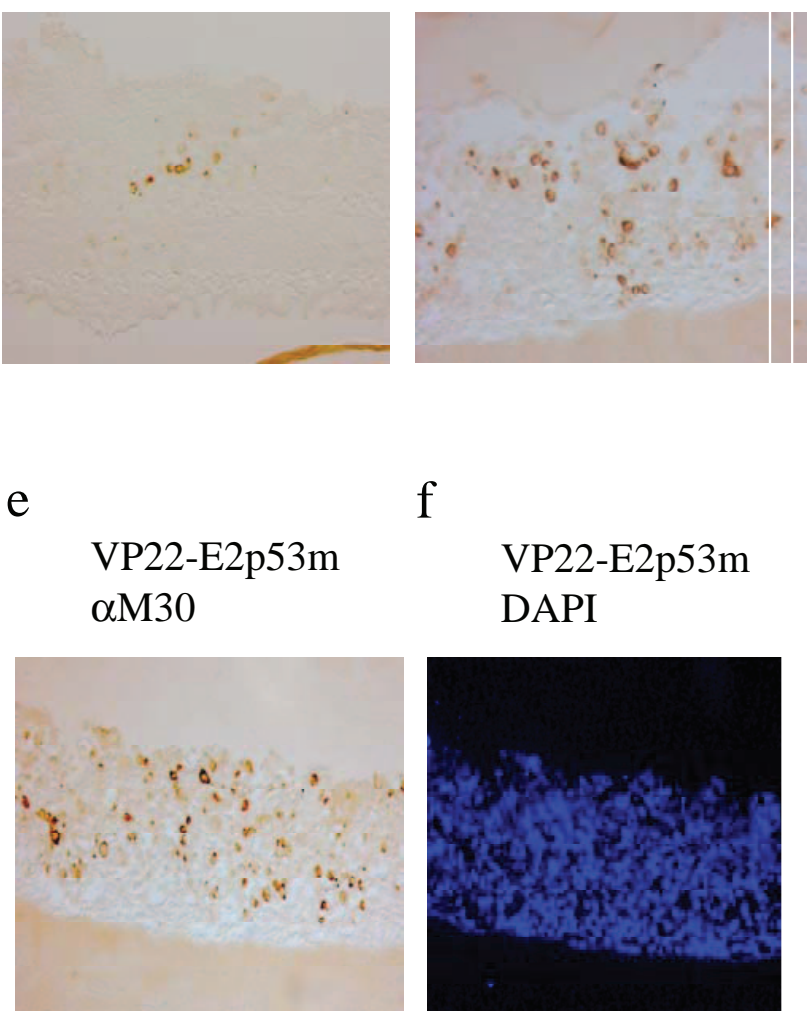

f

VP22-E2p53m

DAPI

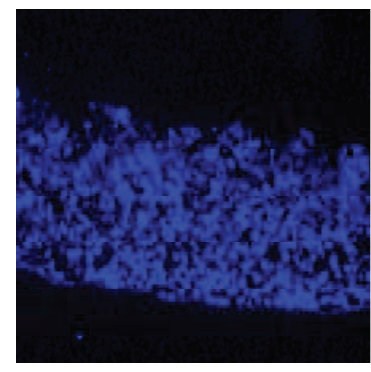

FIG. 7. VP22-E2p53m induces apoptosis in a tumor model. $\mathrm{SiHa}$ cells were grown in organotypic culture before being coinfected with Ad GFP and either Ad VP22 or Ad VP22-E2. After $48 \mathrm{hr}$ the rafts were sectioned and adjacent sections were stained for GFP or VP22 by immunohistochemistry. (a) GFP staining in a raft infected with Ad GFP and Ad VP22. (b) VP22-E2 staining in a raft infected with Ad GFP and Ad VP22-E2. Further sections were stained for apoptotic cells, using the M30 CytoDEATH antibody and immunohistochemistry. (c) Apoptotic cells in a raft infected with Ad GFP and Ad VP22. (d) Apoptotic cells in a raft infected with Ad GFP and Ad VP22-E2. (e) Apoptotic cells in a raft infected with Ad GFP and Ad VP22-E2p53m. (f) A section adjacent to that shown in (e) was stained with DAPI to visualize all the cells in the raft. 
may be advantageous to deliver this protein via a local application at a tumor site. We have shown previously that VP22-E2 proteins purified from bacterial cells can enter mammalian cells and induce apoptosis (Roeder et al., 2004). To determine whether VP22-E2p53m proteins produced in this manner are also able to induce apoptosis in HPV-transformed cells, we purified His-tagged VP22, VP22-E2, and VP22-E2p53m fusion proteins. The purified fusion proteins were then applied to Cos7 cells, HeLa cells, and MCF-7 cells and after $24 \mathrm{hr}$ the levels of apoptosis were determined as described previously. None of the purified proteins induced apoptosis in Cos-7 cells (Fig. 8a). This demonstrates that there were no bacterial toxins or other cytotoxic molecules contaminating the protein preparations. As expected, purified HisVP22 had no effect of the levels of apoptosis in HeLa cells. In contrast, both HisVP22-E2 and HisVP22-E2p53m induced apoptosis in HeLa cells in a dosedependent manner (Fig. 8b). The HisVP22-E2 protein also induced apoptosis in MCF-7 cells in a dose-dependent manner (Fig. 8c). However, the HisVP22-E2p53m protein did not induce apoptosis in these cells. These data demonstrate that pu- a

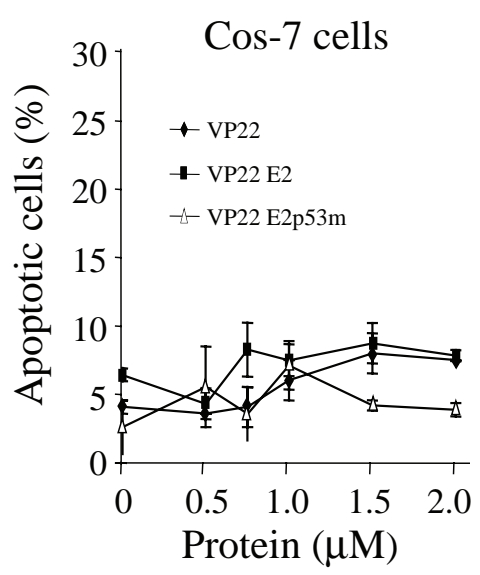

b

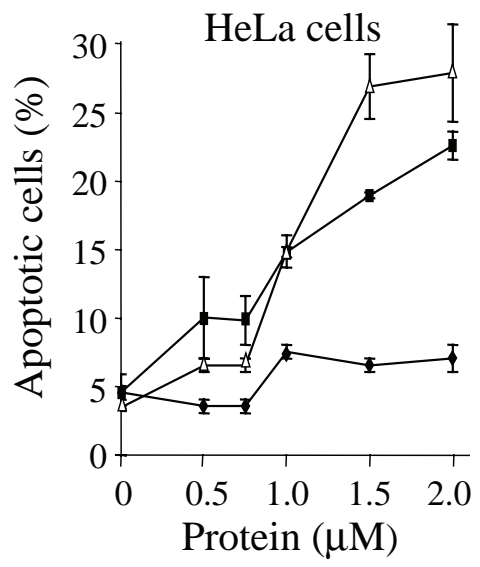

C

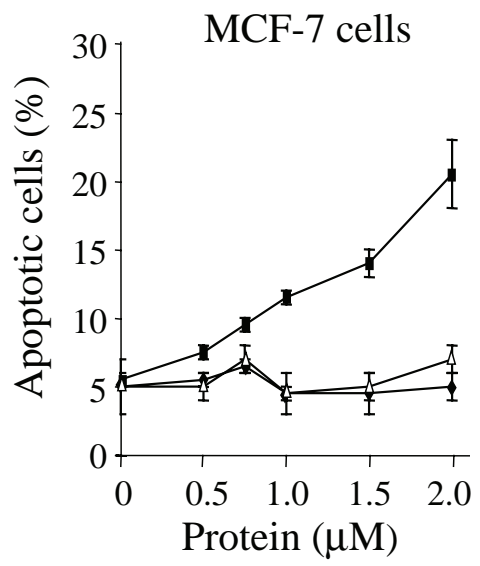

d

Cells only $\alpha$ VP22

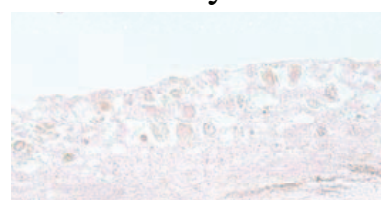

e

\section{VP22-E2 $\alpha$ VP22}

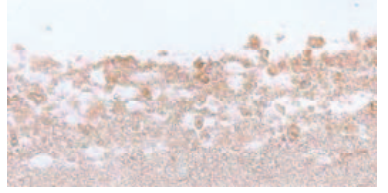

f

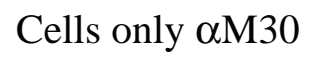

g

\section{VP22 $\alpha \mathrm{M} 30$}

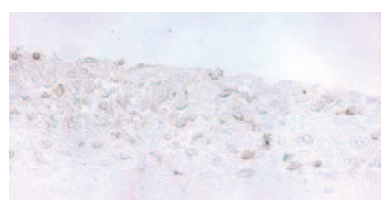

h

\section{VP22-E2 $\alpha \mathrm{M} 30$}

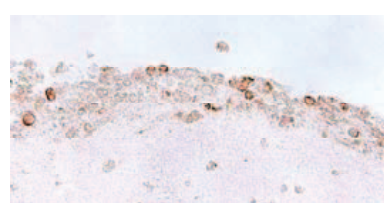

FIG. 8. VP22-E2 fusion proteins produced in bacteria induce apoptosis and penetrate raft cultures. (a) Cos-7 cells were exposed to the concentrations of purified protein indicated for $24 \mathrm{hr}$ at $37^{\circ} \mathrm{C}$ and $5 \%$ $\mathrm{CO}_{2}$. The cells were then fixed and stained and assessed for apoptosis exactly as described previously. (b) HeLa cells were exposed to the concentrations of purified proteins indicated and the number of apoptotic cells was determined as described previously. (c) The experiment described in (a) was repeated with MCF-7 cells. (d-h) Sections from $\mathrm{SiHa}$ rafts. (d) and (e) show sections from an untreated SiHa raft and a raft treated with VP22-E2, respectively, stained with a VP22 antibody exactly as described in Fig. 7. The remaining sections were stained for apoptotic cells, using the M30 antibody exactly as in Fig. 7, and show sections from an untreated $\mathrm{SiHa}$ raft (f), a raft treated with VP22 protein $(\mathbf{g})$, and a raft treated with VP22-E2 protein (h). 
rified HisVP22-E2p53m protein is able to enter human cells and induce apoptosis. Furthermore, the His VP22-E2 protein retains the ability to specifically induce apoptosis in HPV-transformed cells.

To determine whether the purified VP22 fusion proteins are able to penetrate a three-dimensional raft of tumor cells and induce apoptosis in this setting, we next applied the protein to the top surface of SiHa rafts. After $48 \mathrm{hr}$ we embedded the rafts in paraffin and took sections for immunohistochemical staining with VP22 and M30 antibodies. VP22-E2 was present in the treated rafts but not in the untreated rafts and the protein appeared to have penetrated as far as the basal layer (compare Fig. 8d and e). There were few apoptotic cells in the untreated rafts (Fig. 8f) or in the VP22-treated rafts (Fig. 8g), but apoptotic cells were present in large numbers in the VP22-E2-treated rafts (Fig. 8h). In the VP22-E2-treated rafts apoptotic cells appeared to be present as far as the basal layer. These data confirm that the VP22-E2 fusion proteins were able to penetrate the raft and induce apoptosis in this setting.

\section{DISCUSSION}

The papillomavirus E2 proteins have potential as therapeutic agents for cervical cancer and other HPV-induced disease states (Green and Gaston, 2006). However, there are several types of papillomavirus and the E2 proteins from different virus types can display different properties. The bovine papillomavirus (BPV) E2 protein has been shown to induce growth arrest and cellular senescence in HPV-transformed cells. The mechanism whereby the BPV E2 protein brings about these effects on cell proliferation has been elucidated in detail (Dowhanick et al., 1995; Goodwin et al., 1998; Goodwin and DiMaio, 2000). The BPV E2 protein binds to integrated copies of the HPV genome and represses transcription of the E6 and E7 oncogenes, leading to the reestablishment of cell growth control (Goodwin and DiMaio, 2000). The human papillomavirus E2 proteins can also inhibit the growth of HPV-transformed cells by this mechanism (Desaintes et al., 1997). However, we and others have shown that some of the HPV E2 proteins can induce apoptosis in cells that do not contain HPV DNA (Frattini et al., 1997; Desaintes et al., 1999; Webster et al., 2000). These HPV-independent effects of the HPV E2 proteins make it difficult to see how the E2 proteins can be used in cancer therapy. Here we have shown that a mutated HPV$16 \mathrm{E} 2$ protein $(\mathrm{E} 2 \mathrm{p} 53 \mathrm{~m})$ retains the ability to induce apoptosis in HPV-transformed cells but shows significantly reduced ability to induce apoptosis in non-HPV-transformed cells and in four untransformed primary cell types. Use of this mutated E2 protein in cancer therapy would therefore have significant advantages in terms of cell type specificity.

The efficient delivery of therapeutic peptides is also required for effective cancer treatment. We have shown previously that a fusion protein consisting of the HSV-1 VP22 protein fused to the HPV-16 E2 protein can traffic between cells (Roeder et al., 2004; Green et al., 2006). Here we have shown that this approach can be used to deliver the E2p53m protein and that, as in the case of the wild-type E2 protein, the VP22-Ep53m protein is capable of inducing apoptosis. The ability of these fusion proteins to traffic between cells is best demonstrated in three-dimensional raft cultures. In these cultures, VP22 fusion proteins, produced after the application of adenoviral constructs to the top surface of the raft, can be detected in many layers of cells. In contrast, a protein that cannot traffic between cells is restricted to the top few layers of cells within the raft after adenoviral delivery to the raft surface. The fact that not all the cells within the raft stain positive for VP22 proteins effectively excludes the possibility that the trafficking of these proteins is an artifact of fixation as has been suggested previously for other VP22 fusion proteins (Lundberg and Johansson, 2001; Rutjes et al., 2003).

Adenoviral vectors expressing the VP22-E2p53m protein are able to infect a variety of human cell types with high efficiency. VP22-E2p53m produced in infected cells can induce apoptosis if the cells are HPV transformed. However, if the infected cells are untransformed, apoptosis is induced at much lower levels. Furthermore, VP22-E2p53m proteins that are produced in these cells can exit the infected cells and traffic to uninfected bystander cells. If these bystander cells are HPV transformed the trafficked E2p53m proteins can induce apoptosis. This suggests that these or other, similar viruses expressing VP22-E2 fusion proteins might be effective in killing tumor cells while having little effect on normal cells. Another possibility is that these fusion proteins could be delivered to their target cells as purified proteins. We have shown that VP22-E2 and VP22-E2p53m proteins produced in bacterial cells are capable of inducing apoptosis in HeLa and SiHa cells. However, only VP22-E2 induces apoptosis in non-HPV-transformed MCF-7 cells. This protein-based approach would circumvent the need for viral or liposome-based delivery methods and their associated problems. Furthermore, we have shown that these proteins can penetrate $\mathrm{SiHa}$ raft cultures and induce apoptosis in this setting. Delivery of VP22-E2p53m proteins locally postsurgery could assist in the elimination of any remaining tumor cells. This may prove to be beneficial in the treatment of cervical cancer and other HPV-induced diseases.

\section{ACKNOWLEDGMENTS}

The authors are grateful to Dr. Peter O'Hare for VP22 antibodies and to Dr. Peter Stern for many of the cell lines used in this work and for useful discussions. Katie Green is grateful to the BBSRC and Protherics Plc for a CASE Ph.D. studentship. T.D.S. is supported by CRUK. K.G. and C.B. are supported by the Wellcome Trust.

\section{DISCLOSURE STATEMENT}

The authors declare that no competing financial interests exist.

\section{REFERENCES}

BAKER, C.C., PHELPS, W.C., LINDGREN, V., BRAUN, M.J., GONDA, M.A., and HOWLEY, P.M. (1987). Structural and transcriptional analysis of human papillomavirus type 16 sequences in cervical carcinoma cell lines. J. Virol. 61, 962-971. 
BASTA, A., ADAMEK, K., and PITYNSKI, K. (1999). Intraepithelial neoplasia and early stage vulvar cancer: Epidemiological, clinical and virological observations. Eur. J. Gynaecol. Oncol. 20, 111-114.

BECKMANN, A.M., KIVIAT, N.B., DALING, J.R., SHERMAN, K.J., and MCDOUGALL, J.K. (1988). Human papillomavirus type 16 in multifocal neoplasia of the female genital tract. Int. J. Gynecol. Pathol. 7, 39-47.

BIGLARI, A., SOUTHGATE, T.D., FAIRBAIRN, L.J., and GILHAM, D.E. (2006). Human monocytes expressing a CEA-specific chimeric CD64 receptor specifically target CEA expressing tumour cells in vitro and in vivo. Gene Ther. 13, 602-610.

BRAY, F., LOOS, A.H., McCARRON, P., WEIDERPASS, E., ARBYN, M., MOLLER, H., HAKAMA, M., and PARKIN, D.M. (2005). Trends in cervical squamous cell carcinoma incidence in 13 European countries: Changing risk and the effects of screening. Cancer Epidemiol. Biomarkers Prev. 14, 677-686.

COLEMAN, M.P., RACHET, B., WOODS, L.M., MITRY, E., RIGA, M., COOPER, N., QUINN, M.J., BRENNER, H., and ESTEVE, J. (2004). Trends and socioeconomic inequalities in cancer survival in England and Wales up to 2001. Br. J. Cancer 90, 1367-1373.

CORDEN, S.A., SANT-CASSIA, L.J., EASTON, A.J., and MORRIS, A.G. (1999). The integration of HPV-18 DNA in cervical carcinoma. Mol. Pathol. 52, 275-282.

DELL, G., and GASTON, K. (2001). Human papillomaviruses and their role in cervical cancer. Cell. Mol. Life Sci. 58, 1923-1942.

DELVENNE, P., HUBERT, P., JACOBS, N., GIANNINI, S.L., HAVARD, L., RENARD, I., SABOULARD, D., and BONIVER, J. (2001). The organotypic culture of HPV-transformed keratinocytes: An effective in vitro model for the development of new immunotherapeutic approaches for mucosal (pre)neoplastic lesions. Vaccine 19, 2557-2564.

DESAINTES, C., DEMERET, C., GOYAT, S., YANIV, M., and THIERRY, F. (1997). Expression of the papillomavirus E2 protein in HeLa cells leads to apoptosis. EMBO J. 16, 504-514.

DESAINTES, C., GOYAT, S., GARBAY, S., YANIV, M., and THIERRY, F. (1999). Papillomavirus E2 induces p53-independent apoptosis in HeLa cells. Oncogene 18, 4538-4545.

DOWHANICK, J.J., MCBRIDE, A.A., and HOWLEY, P.M. (1995). Suppression of cellular proliferation by the papillomavirus E2 protein. J. Virol. 69, 7791-7799.

DREYER, G. (2005). Operative management of cervical cancer. Best Pract. Res. Clin. Obstet. Gynaecol. 19, 563-576.

DURST, M., KLEINHEINZ, A., HOTZ, M., and GISSMAN, L. (1985). The physical state of human papillomavirus type 16 DNA in benign and malignant genital tumours. J. Gen. Virol. 66, 1515-1522.

DYSON, N., HOWLEY, P.M., MUNGER, K., and HARLOW, E. (1989). The human papilloma virus-16 E7 oncoprotein is able to bind to the retinoblastoma gene product. Science 243, 934-937.

ELLIOTT, G., and O'HARE, P. (1999). Intercellular trafficking of VP22-GFP fusion proteins. Gene Ther. 6, 149-151.

FRANCIS, D.A., SCHMID, S.I., and HOWLEY, P.M. (2000). Repression of the integrated papillomavirus E6/E7 promoter is required for growth suppression of cervical cancer cells. J. Virol. 74, 2679-2686.

FRATTINI, M.G., HURST, S.D., LIM, H.B., SWAMINATHAN, S., and LAIMINS, L.A. (1997). Abrogation of a mitotic checkpoint by E2 proteins from oncogenic human papillomaviruses correlates with increased turnover of the p53 tumor suppressor protein. EMBO J. 16, 318-331.

GOODWIN, E.C., and DIMAIO, D. (2000). Repression of human papillomavirus oncogenes in HeLa cervical carcinoma cells causes the orderly reactivation of dormant tumor suppressor pathways. Proc. Natl. Acad. Sci. U.S.A. 97, 12513-12518.

GOODWIN, E.C., NAEGER, L.K., BREIDING, D.E., ANDROPHY, E.J., and DIMAIO, D. (1998). Transactivation-competent bovine papillomavirus E2 protein is specifically required for efficient repres- sion of human papillomavirus oncogene expression and for acute growth inhibition of cervical carcinoma cell lines. J. Virol. 72, 3925-3934.

GREEN, K.L., and GASTON, K. (2006). Development of a topical protein therapeutic for human papillomavirus and associated cancers. BioDrugs 20, 209-218.

GREEN, K.L., SOUTHGATE, T.D., MULRYAN, K., FAIRBAIRN, L.J., STERN, P.L., and GASTON, K. (2006). Diffusible VP22-E2 protein kills bystander cells and offers a route for cervical cancer gene therapy. Hum. Gene Ther. 17, 147-157.

HUBERT, P., VAN DEN BRULE, F., GIANNINI, S.L., FRANZEN-DETROOZ, E., BONIVER, J., and DELVENNE, P. (1999). Colonization of in vitro-formed cervical human papillomavirus-associated (pre)neoplastic lesions with dendritic cells: Role of granulocyte/macrophage colony stimulating factor. Am. J. Pathol. 154, 775-784.

HWANG, E.S., RIESE, D.J., SETTLEMAN, J., NILSON, L.A., HONIG, J., FLYNN, S., and DIMAIO, D. (1993). Inhibition of cervical carcinoma cell line proliferation by the introduction of a bovine papillomavirus regulatory gene. J. Virol. 67, 3720-3729.

HWANG, E.S., NAEGER, L.K., and DIMAIO, D. (1996). Activation of the endogenous p53 growth inhibitory pathway in HeLa cervical carcinoma cells by expression of the bovine papillomavirus E2 gene. Oncogene 12, 795-803.

JONES, D.L., THOMPSON, D.A., and MUNGER, K. (1997). Destabilization of the RB tumor suppressor protein and stabilization of p53 contribute to HPV type 16 E7-induced apoptosis. Virology 239, 97-107.

KALANTARI, M., KARLSEN, F., KRISTENSEN, G., HOLM, R., HAGMAR, B., and JOHANSSON, B. (1998). Disruption of the E1 and $\mathrm{E} 2$ reading frames of HPV 16 in cervical carcinoma is associated with poor prognosis. Int. J. Gynecol. Pathol. 17, 146-153.

KITCHENER, H. (2002). Evidence-based medicine applied to cervical cancer. Virus Res. 89, 175-181.

KOWALCZYK, A.M., ROEDER, G.E., GREEN, K., STEVENS, D.J., and GASTON, K. (2005). Measuring the induction or inhibition of apoptosis by HPV proteins. In Human Papilloma Viruses: Methods and Protocols. J. Doorbar and C. Davy, eds. (Humana Press, Totowa, NJ).

KUSAMA, K., JIANG, Y., TOGUCHI, M., OHNO, J., SHIKATA, H., SAKASHITA, H., and SAKAGAMI, H. (2000). Use of the monoclonal antibody M30 for detecting HSG cell apoptosis. Anticancer Res. 20, 151-154.

LUNDBERG, M., and JOHANSSON, M. (2001). Is VP22 nuclear homing an artifact? Nat. Biotechnol. 19, 713-714.

MASSIMI, P., PIM, D., BERTOLI, C., BOUVARD, V., and BANKS, L. (1999). Interaction between the HPV-16 E2 transcriptional activator and p53. Oncogene 18, 7748-7754.

MIETZ, J.A., UNGER, T., HUIBREGTSE, J.M., and HOWLEY, P.M. (1992). The transcriptional transactivation function of wild-type p53 is inhibited by SV40 large T-antigen and by HPV-16 E6 oncoprotein. EMBO J. 11, 5013-5020.

MUNGER, K., PHELPS, W.C., BUBB, V., HOWLEY, P.M., and SCHLEGEL, R. (1989a). The E6 and E7 genes of the human papillomavirus type 16 together are necessary and sufficient for transformation of primary human keratinocytes. J. Virol. 63, 4417-4421.

MUNGER, K., WERNESS, B.A., DYSON, N., PHELPS, W.C., HARLOW, E., and HOWLEY, P.M. (1989b). Complex formation of human papillomavirus E7 proteins with the retinoblastoma tumor suppressor gene product. EMBO J. 8, 4099-4105.

MUNGER, K., YEE, C.L., PHELPS, W.C., PIETENPOL, J.A., MOSES, H.L., and HOWLEY, P.M. (1991). Biochemical and biological differences between E7 oncoproteins of the high- and lowrisk human papillomavirus types are determined by amino-terminal sequences. J. Virol. 65, 3943-3948.

NISHIMURA, A., ONO, T., ISHIMOTO, A., DOWHANICK, J.J., FRIZZELL, M.A., HOWLEY, P.M., and SAKAI, H. (2000). Mech- 
anisms of human papillomavirus E2-mediated repression of viral oncogene expression and cervical cancer cell growth inhibition. J. Virol. 74, 3752-3760.

PARISH, J., KOWALCZYK, A.M., CHEN, H., ROEDER, G.E., SESSIONS, R., BUCKLE, M., and GASTON, K. (2006). The E2 proteins from high- and low-risk HPV types differ in their ability to bind p53 and induce apoptotic cell death. J. Virol. 80, 4580-4590.

PARKIN, D.M., BRAY, F., FERLAY, J., and PISANI, P. (2005). Global cancer statistics, 2002. CA Cancer J. Clin. 55, 74-108.

PFISTER, H. (1992). Human papillomaviruses and skin cancer. Semin. Cancer Biol. 3, 263-271.

PHELAN, A., ELLIOTT, G., and O'HARE, P. (1998). Intercellular delivery of functional p53 by the herpesvirus protein VP22. Nat. Biotechnol. 16, 440-443.

ROEDER, G.E., PARISH, J.L., STERN, P.L., and GASTON, K. (2004). Herpes simplex virus VP22-human papillomavirus E2 fusion proteins produced in mammalian or bacterial cells enter mammalian cells and induce apoptotic cell death. Biotechnol. Appl. Biochem. 40, 157-165.

ROMANCZUK, H., and HOWLEY, P.M. (1992). Disruption of either the E1 or the E2 regulatory gene of human papillomavirus type 16 increases viral immortalization capacity. Proc. Natl. Acad. Sci. U.S.A. 89, 3159-3163.

RUTJES, S.A., BOSMA, P.J., ROHN, J.L., NOTEBORN, M.H., and WESSELING, J.G. (2003). Induction of insolubility by herpes simplex virus VP22 precludes intercellular trafficking of N-terminal apoptin-VP22 fusion proteins. J. Mol. Med. 81, 558-565.

SANCHEZ-PEREZ, A.M., SORIANO, S., CLARKE, A.R., and GASTON, K. (1997). Disruption of the human papillomavirus type 16 E2 gene protects cervical carcinoma cells from E2F-induced apoptosis. J. Gen. Virol. 78, 3009-3018.

SCHEFFNER, M., WERNESS, B.A., HUIBREGTSE, J.M., LEVINE, A.J., and HOWLEY, P.M. (1990). The E6 oncoprotein encoded by human papillomavirus types 16 and 18 promotes the degradation of p53. Cell 63, 1129-1136.

SCHWARTZ, S.M., DALING, J.R., DOODY, D.R., WIPF, G.C., CARTER, J.J., MADELEINE, M.M., MAO, E.J., FITZGIBBONS, E.D., HUANG, S., BECKMANN, A.M., MCDOUGALL, J.K., and GALLOWAY, D.A. (1998). Oral cancer risk in relation to sexual history and evidence of human papillomavirus infection. J. Natl. Cancer Inst. 90, 1626-1636.

SCHWARZ, E., FREESE, U.K., GISSMANN, L., MAYER, W., ROGGENBUCK, B., STREMLAU, A., and ZUR HAUSEN, $\mathrm{H}$. (1985). Structure and transcription of human papillomavirus sequences in cervical carcinoma cells. Nature 314, 111-114.

STERN, P.L. (2005). Immune control of human papillomavirus (HPV) associated anogenital disease and potential for vaccination. J. Clin. Virol. 32(Suppl. 1), S72-S81.
STOREY, A., PICCINI, A., MASSIMI, P., BOUVARD, V., and BANKS, L. (1995). Mutations in the human papillomavirus type 16 E2 protein identify a region of the protein involved in binding to E1 protein. J. Gen. Virol. 76, 819-826.

STROH, C., HELD, J., SAMRAJ, A.K., and SCHULZE-OSTHOFF, K. (2003). Specific inhibition of transcription factor NF- $\kappa$ B through intracellular protein delivery of $\mathrm{I} \kappa \mathrm{B} \alpha$ by the herpes virus protein VP22. Oncogene 22, 5367-5373.

THAIN, A., WEBSTER, K., EMERY, D., CLARKE, A.R., and GASTON, K. (1997). DNA binding and bending by the human papillomavirus type $16 \mathrm{E} 2$ protein: Recognition of an extended binding site. J. Biol. Chem. 272, 8236-8242.

VOUSDEN, K.H. (2002). Activation of the p53 tumor suppressor protein. Biochim. Biophys. Acta 1602, 47-59.

WALBOOMERS, J.M., JACOBS, M.V., MANOS, M.M., BOSCH, F.X., KUMMER, J.A., SHAH, K.V., SNIJDERS, P.J., PETO, J., MEIJER, C.J., and MUNOZ, N. (1999). Human papillomavirus is a necessary cause of invasive cervical cancer worldwide. J. Pathol. 189, $12-19$.

WEBSTER, K., PARISH, J., PANDYA, M., STERN, P.L., CLARKE, A.R., and GASTON, K. (2000). The human papillomavirus (HPV) 16 E2 protein induces apoptosis in the absence of other HPV proteins and via a p53-dependent pathway. J. Biol. Chem. 275, 87-94.

YANG, B.H., BRAY, F.I., PARKIN, D.M., SELLORS, J.W., and ZHANG, Z.F. (2004). Cervical cancer as a priority for prevention in different world regions: An evaluation using years of life lost. Int. J. Cancer 109, 418-424.

YEE, C., KRISHNAN-HEWLETT, I., BAKER, C.C., SCHLEGEL, R., and HOWLEY, P.M. (1985). Presence and expression of human papillomavirus sequences in human cervical carcinoma cell lines. Am. J. Pathol. 119, 361-366.

Address reprint requests to: Dr. Kevin Gaston Department of Biochemistry University of Bristol Bristol BS8 1TD, UK

E-mail: Kevin.Gaston@Bristol.ac.uk

Received for publication March 20, 2006; accepted after revision May 2, 2007.

Published online: June 15, 2007. 